\title{
䣃尔多斯地区中-晚石炭世 海沼沙岭沉积体系
}

\author{
陈昌明 汪寿松 黄家宽 陈志明 柯保嘉 \\ (中国科学院地质研究所,北京) \\ 陈安宁 \\ (长庆石油勘探局)
}

关调海沼沙沉积体系、细碎眉含煤层序、现立砂体、大聚煤和媒成气区

在加里东旋回的晚期, 鄂尔多斯地区与整个华北地台一起抬升遭受侵蚀,至华力西旅回中

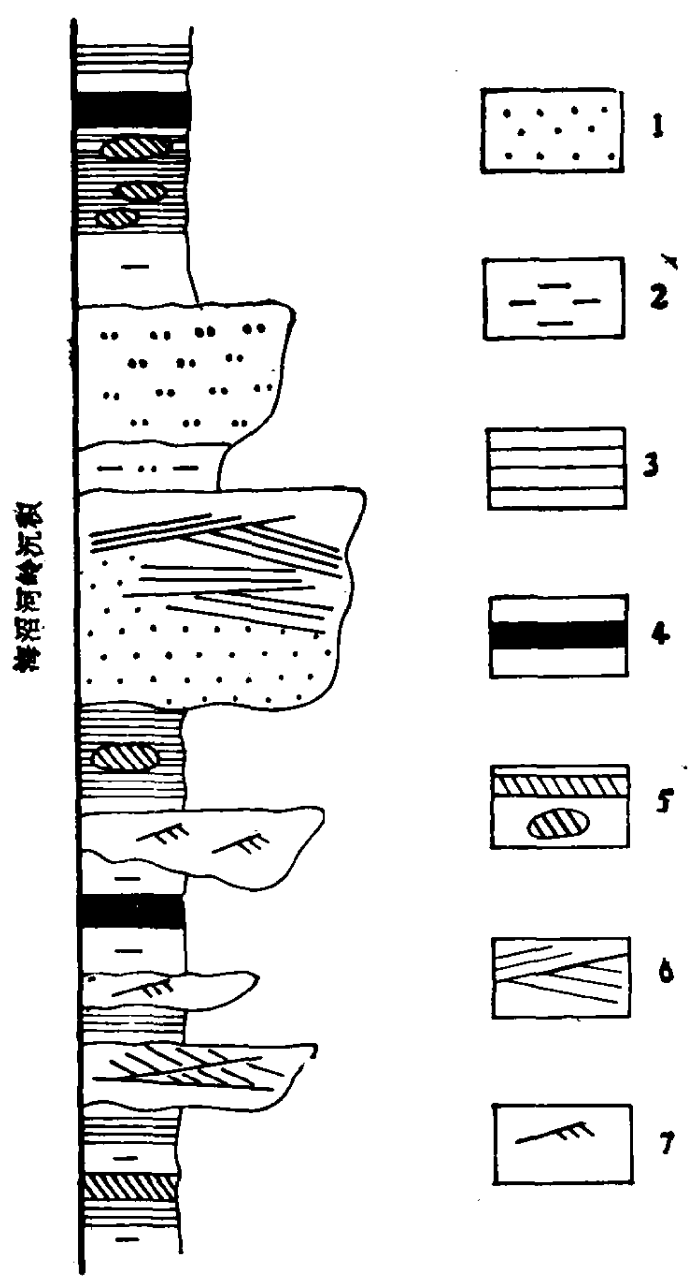

图 1 夹于含煤层序中的海沼沙岭平原沉积层序, 山西省柳林县上石炭统太原组下部

1.砂岩；2.泥岩；3.页岩；4.媒层；5.菱铁矿夹层和结校；6.低角度交错层理；7.小波痕交错层国

本文 1988 年12月28日收到。 


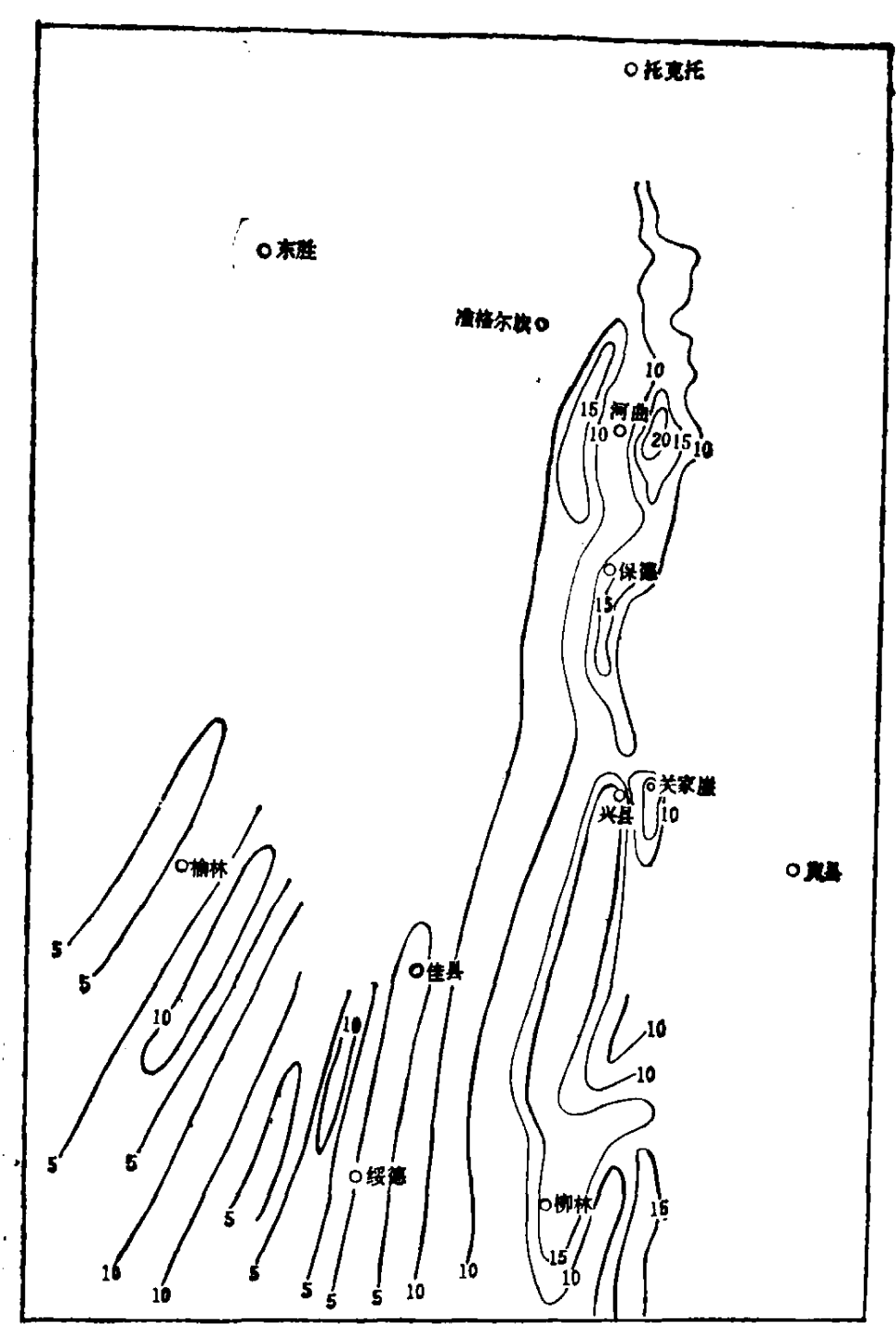

图 2 太原组底部晋祠砂岩等厚图

期鄂尔多斯地区又发生沉降, 导致该区最后一次海侵. 中石炭世一晚石炭世早期, 华北海和祁 连海分别从东西两面进人本区, 被本区中部南北向“工”字形隆起区隔开, 从而在此古陆的东西 两侧各形成了一套海岸沉积. 东部海岸在中石炭统本溪组上部和上石炭统太原组下部, 西部 海岸在中石炭统羊虎沟组上部和上石炭统太原组下部发育了一套海沼沙岭 (chenier) 平原沉 积体系。

海沼沙岭平原沉积的主要特征是在细碎屑(含丰富菱铁矿条带和结核的黑色页岩、碳质页 岩、泥岩、粉砂质页岩)的含煤层系中夹有粗碎屑的孤立砂体 (图 1). 砂岩成熟度高, 主要由石 英砂组成, 有时含少量海相生物化石, 具有向上变粗的反旋回粒度变化或粒度变化不明显的特 征. 砂岩体内部构造以低角度交错层理和楔状交错层理为主, 西部海沼沙岭砂体底部常见大 型交错层理,砂体厚度一般 2-4m, 最厚可达 8-10m. 横剖面呈透镜状, 沿走向延伸较长, 呈条带状平行海岸排列。

已发现东部太原组底部的晋祠砂岩呈八个条带由西向东平行于东海岸排列(图 2). 这些 砂体形成于海沼沙岭发育的不同时期, 但时间上相隔不长. 砂岩体一般断续延伸, 长达几十到 
上百公里; 砂体䆓约 5-10km; 砂体间相隔约 3-5km－一杪之间为近岸沼泽或泥坪含煤沉 积. 该区的海沿沙岭平原沉积内含有大量的菱铁矿结核和条带以及少量白云岩, 说明沼泽区 局部为泻湖占海沼沙岭平原沉积体系之上为比较典型的潮汐沉积, 包括潮间混合坪、沙 坪、泻湖和湖道沉积. 东部海岸的海沼沙岭平原沉积体系之上为约代尔型 ${ }^{[1,2]}$ 浅海陆源碎首一 碳酸盐含煤旋靣沉积. 由于西部潮为作用强，沙脊之间的间隔更小，形成的础岩体也更多.

上述沉积体系可与美国得克萨斯州东南部密西西比河三角洲以西墨西哥沿岸发育良好的 现代海沼沙岭平原沉积体系对比 ${ }^{[1-61}$. 其成因是河流三角洲提供的以细碎屑物质为主的陆游 物由沿岸流投运到三角洲侧旁大量沉积下来,形成广阔的海岸沼泽和/或泥坪, 当陆源物供应 减少时, 海洋的政造作用占优势, 波浪和潮为水流将细碎屑物携带到滨外, 留下的粗碎首物堆: 积成沙脊. 波浪和水流的冲珗作用在砂体内形成低角度交错层理和契状交错层理. 本区西部 海岸砂体下部的槽状交错层理则可能与强潮汐水流形成的新月形大波痕有关. 当陆源物供绘 再度增加时就刉起沙脊前新沼泽和/或泥坪的形成和向海推进,结果抓立的沙脊被四周的沼泽 所包围可. 这种变化既与三角洲朵叶的迁移、废弃和复活有关, 也与源区的局部构造活动有 关.

海沙岭平原沉积体系是有利的海相成煤环境。从垂向剖面上看, 在海沼沙岭上下或砂 体之间可以找到煤的聚集层位; 从区域分布上看,在海沼沙岭的向陆一侧或沙岭之间可以找到 有利于成煤的沼泽环境. 目前在所研究的东、西部海沼沙岭平原沉规体系内均已发现了煤圤 或煤层. 此外该体系还可望成为煤成气的良好生储盖组合.

研究海沼沙岭平原沉积还有助于饭复区域岩相古地理, 因为该沉积指示了海岸线的位置. 和海陆的方向. 这对寻找同时期的三角洲和其它海岸沉积体系大有禆益.

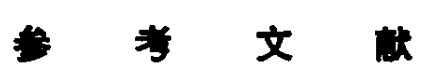

[1] Wang Shousong et al., Chinese Science Bull., 1989 (in press).

[ 2] Wilson, J. L., Carbonare Facies in Geological History. Springer-Verlag. New Yark, Heidelberg, Berlin, 1975.

[ 3 ] Reineck, H. E. and Singh, 1. B., Depositional Sedimentary Environments, 2nd ed., Springer-Verlag. Berlin, Heidlberg, New York, 1980.

[4] Reineck, H. E., Geol. Rundschan, 60(1970b), 302-321.

[5] Byrne, J. V., Leroy, D. O., Riley, C. M., Trans. Gulf Coast Association Geological Society 9th Annual Meeting, Houston, 2(1959), 237-260.

[6] Gould, H. R., Mcfarlan, Jr. E., Trans. Gulf Coast Associetion Geological Society. 9zh Annwal Macting, Houston. 9(1959), 261-270.

[ 7 ] Hoyt, J. H., Bull. AAPG, 53(1969), 299-306. 